\title{
Fluctuating asymmetry in Ichthyophonus-sp. infected newts, Notophthalmus viridescens, from Vermont
}

\author{
Elizabeth Sherman ${ }^{1}$, Kaylee Tock and Casey Clarke \\ Natural Sciences and Mathematics, Bennington College, Bennington, VT 05201, USA \\ ${ }^{1}$ Corresponding author; e-mail: Sherman@bennington.edu
}

\begin{abstract}
Measures of fluctuating asymmetry (FA) have been used to assess the significance of stress in amphibian populations. When animals with bilateral body plans are challenged by environmental stressors, departures from bilateral symmetry can emerge during development. The tendency for FA to develop has been linked to greater susceptibility to pathogens in many organisms. In our study, newts (Notophthalmus viridescens) infected with Ichthyophonus-sp. exhibited greater size-corrected FA of the hind limbs than uninfected animals from the same population. Among infected animals, however, the intensity of infection and the extent of hind limb asymmetry were not correlated, suggesting that asymmetry did not arise following infection, but rather that newts having greater FA may have been more susceptible to infection as a result of the same stresses that produced the increase in FA. There was no relationship between dorsal spot pattern FA and infection status or hind limb FA. We suggest that spot pattern may be less canalized than hind limb development. Newts are widely distributed and important components of freshwater communities in eastern North America and, thus, any change in their vitality may affect the composition of those communities. Analyses of hind limb FA may be a useful and non-invasive tool for identifying potentially vulnerable amphibian populations.
\end{abstract}

(C) Koninklijke Brill NV, Leiden, 2009

Key words

Amphibian conservation, fluctuating asymmetry, Ichthyophonus-sp., infection, newts, pathogen.

\section{Introduction}

Global climate change has been implicated in the increased incidence of infections in amphibians (Carey and Alexander, 2003; Pounds et al., 2006). These infections, in turn, have been associated with amphibian population declines (Blaustein and Wake, 1990; Carey, 2000; Daszak et al., 1999, 2003). While the red-spotted newt, Notophthalmus viridescens, is not considered a threatened species (Global Amphibian Assessment), reports of Ichthyophonus-like infections in newts have linked those infections to increases in newt morbidity and mortality (Green et al., 2002; Mikaelian et al., 2000). Ichthyophonus-sp. infected newts display characteristic le- 
sions of longitudinally arrayed swellings or more discrete nodules in the axial musculature (Hermann, 1984; Raffel et al., 2006). Ichthyophonus-sp. infections have been reported in a number of different anuran amphibians including Rana catesbiana, $R$. sylvatica, $R$. clamitans, $R$. palustris, and Pseudacris crucifer (Green et al., 2002; Mikaelian et al., 2000). As far as we know, red-spotted newts are the only salamanders to exhibit this infection. Ultrastructurally, the Ichthyophonus-like organism in amphibians resembles the fish parasite Ichthyophonus hoferi (Mikaelian et al., 2000). However, unlike Ichthyophonus hoferi, which is transmitted trophically in fish, Ichthyophonus-sp. at least among newts, appears to be transmitted through leech bites (Raffel et al., 2006). The taxonomy of the organism that resembles Ichthyophonus and parasitizes amphibians remains unclear. Currently, the organism is classified within the Mesomycetozoa (Green et al., 2002; Raffel et al., 2006).

Newts are important predators in freshwater communities in eastern North America and their presence has significant consequences for the structures of those communities (Smith, 2006). In addition to increases in newt morbidity and mortality, the locomotor abilities of Ichthyophonus-infected newts might be compromised (Raffel et al., 2006), which could make foraging and escaping from predators more difficult. Further, the lesions can ulcerate and become secondarily infected with lethal bacteria (Herman, 1984; Raffel et al., 2006).

The conservation of amphibians requires an understanding of the relationship between parasites and their amphibian hosts (Collins and Storfer, 2003; Daszak et al., 2003). Scientists have sought appropriate measures to monitor the vulnerability of individual amphibians and the populations to which they belong. Fluctuating asymmetry (FA) is a measure of the degree to which structures that are bilaterally symmetrical depart from perfect symmetry. It results from failures of developmental regulation (Kellner and Alford, 2003), and Alford et al. (1999) suggested that the frequency of such failures should increase with levels of environmental stress, making FA measurements a useful tool for monitoring stress levels in amphibian populations. FA in salamanders with infections has yet to be reported, although chytrid infections have been associated with greater FA in frogs (Parris and Cornelius, 2004). The frogs acquired these infections in the laboratory, however. Additionally, Alford et al. (2007) demonstrated that levels of FA increased dramatically in frog populations well in advance of population crashes caused by chytridiomycosis. To our knowledge, our study is the first to analyze FA in salamanders that acquired their infections in the wild. We compared FA in newts infected with the Ichthyophonus-like organism to that of apparently healthy newts from the same pond. We used two different measures of FA, one for a metric trait, size-corrected differences between right and left hind limbs (index FA2 of Palmer, 1994) and one for a meristic trait, the difference in dorsal spot number between right and left sides (Davis and Maerz, 2007). The utility of FA in providing insights into the robustness of amphibian populations has proven controversial because FA is not always a predictor of other more conventional measures of fitness such as size (McCoy and 
Harris, 2003; Møller, 2006). Therefore, we also measured the mass of infected and uninfected newts.

\section{Material and methods}

Infected and uninfected adult male newts, Notophthalmus viridescens, were collected during July 2003, June 2006, and June 2009 from Wood Pond, a 0.9 ha pond in the foothills of the Taconic Mountains in southern Vermont, and brought back to the laboratory, each in a separate container. Newts were collected haphazardly without regard to their infection status. Collecting nets and containers were thoroughly cleaned with a bleach solution and rinsed after each collection event.

The lesions caused by Ichthyophonus-sp., ranging from small discrete longitudinally arrayed protuberances to larger swellings that affected over half of the animal, are apparent and characteristic of that pathogen (Herman, 1984; Mikaelian et al., 2000; Raffel et al., 2006). A substantial proportion of the newts we collected exhibited such lesions. We sent several apparently infected newts to the National Wildlife Health Center in Madison, Wisconsin, which identified the lesions as having been caused by an Ichthyophonus-like organism. Thereafter, we used visual inspection to designate newts as either uninfected or infected (Raffel et al., 2006; Sherman, 2008). It is unlikely that apparently healthy newts had subclinical infections (Raffel et al., 2006). None of the animals we measured had severe, ulcerated infections.

\section{Maintenance of newts in the laboratory}

Apparently healthy (uninfected) and infected newts were maintained in separate aquaria of no more than six animals per 401 of aged tap water at a temperature of $24( \pm 1)^{\circ} \mathrm{C}$ and natural light (roughly 14:10 L:D). Newts were fed white worms (Enchytraeus sp.) on alternate days and the water was changed every two days. Newts were measured within seven days of collection.

\section{Measurements}

We collected 87 newts (20 uninfected and 13 infected newts in 2003; 11 uninfected and 8 infected newts in 2006; 20 uninfected and 15 infected newts in 2009) and recorded body masses (to the nearest $\mathrm{mg}$ ). Dorsal view digital photographs of each newt were used for the FA analysis. Prior to being photographed, newts were anesthetized in MS222 and placed ventral side down on a piece of Plexiglas at a fixed distance below a digital camera. Care was taken to position each newt directly under the camera with its limbs at a $90^{\circ}$ angle from the long axis of its body before its photograph was taken. The digital photographs were then analyzed using NIH Image software. In order to reduce measurement error (Palmer, 1994), three independent measures of right hind limbs and left hind limbs were taken from the mid-point of limb attachment to the tip of the longest digit (Alford et al., 1999; Davis and Maerz, 2007). 
For the measure of asymmetry of the hind limbs we used the absolute value of the difference between average right and left hind limb lengths divided by half the value of right plus left hind limb length (Palmer's index FA2, 1994) which eliminates differences in overall body size as a confounding variable. We also determined the absolute value of the difference in right versus left dorsal spot number as our measure of FA for a meristic trait. Some photographs could not be analyzed and, thus, the sample size is smaller than the number of newts collected. One infected newt collected in 2006 was eliminated from analysis due to marked deformation of unknown origin of one of its hind limbs. Hind limbs of all other infected newts were not obviously distorted by the infection itself. Lesions were found along the longitudinal axis of the body and never on the limbs. Moreover, while the area of the spots might be affected by skin stretched due to lesions, the absolute number of spots was unlikely to change (Gill, 1978).

\section{Extent of lesions}

To estimate the effectiveness of Ichthyophonus-sp. infection as a predictor of FA, we followed Sherman's (2008) procedure for indexing infection. Characteristically, the lesions were arrayed along the long axis of the newt and could affect one side or both right and left sides of the animal. For each individual collected in 2006 and 2009, infection intensity was estimated as the sum of the lengths of the lesions along the sides in which it was present, divided by the total length of the animal.

\section{Statistical analyses}

We estimated the significance of between individual variation in FA2 with a mixed model two-way ANOVA using the repeated measures of hind limb length with individual as a random effect and side as a fixed effect (Palmer, 1994). Infected and uninfected animals were analyzed separately. In both cases, FA was much greater than measurement error as evidenced by the significant interaction of side $x$ individual (infected $p<0.001$; uninfected $p<0.001$ ). This analysis also revealed that the side effect was not significant (infected $p=0.66$; uninfected $p=0.77$ ), eliminating directional asymmetry from consideration. Finally, we ruled out antisymmetry with Kolmogorov-Smirnov tests for differences from normality of right - left hind limb lengths (Parris and Cornelius, 2004). The values of neither infected $(p>0.1)$ nor uninfected $(p>0.1)$ animals were significantly different from 0 . Collectively, these analyses provided confidence that we were estimating true fluctuating asymmetry (Palmer, 1994).

We performed separate ANOVAs using collection year $(2003,2006,2009)$ and status (infected or uninfected) as fixed factors and mass or the two different measures of FA as dependent variables. Lastly, we performed regression analyses to determine if particular measures of newt phenotype were predictors of other such measures. 


\section{Results}

Body mass of uninfected and infected newts did not differ significantly during any of the three collection years (table 1). However, infected newts exhibited significantly greater FA2 than uninfected newts (fig. 1). The results of the ANOVA (table 2) indicated that disease status was the only significant contributor to variation in FA2 $(p<0.001)$.

Table 1.

Summary of ANOVA for effects of collection year (2003, 2006, 2009), status (uninfected or infected), and their interaction on mass.

\begin{tabular}{lrll}
\hline Source of variation & df & $F$ & $p$ \\
\hline Year & 2 & 0.438 & 0.599 \\
Status & 1 & 4.155 & 0.698 \\
Year $\times$ status & 2 & 1.993 & 0.412 \\
Residual & 80 & & \\
\hline
\end{tabular}

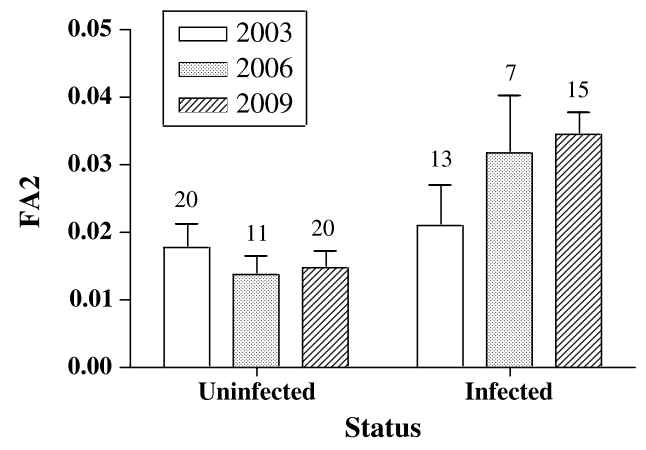

Figure 1. Mean hind leg fluctuating asymmetry ( $\pm 1 \mathrm{SE})$ of uninfected and infected newts of all three collection years. The measure of fluctuating asymmetry is FA2 (Palmer, 1994). FA2 $=|\mathrm{R}-\mathrm{L}| /$ size, where $\mathrm{R}=$ right hind leg length, $\mathrm{L}=$ left hind leg length and size $=(\mathrm{R}+\mathrm{L}) / 2$. Results of ANOVA in table 2.

\section{Table 2.}

Summary of ANOVA for effects of collection year (2003, 2006, 2009), status (uninfected or infected), and their interaction on hind limb FA2.

\begin{tabular}{lccc}
\hline Source of variation & df & $F$ & \multicolumn{1}{c}{$p$} \\
\hline Year & 2 & 0.756 & 0.473 \\
Status & 1 & 14.79 & $<0.001$ \\
Year $\times$ status & 2 & 2.175 & 0.12 \\
Residual & 80 & & \\
\hline
\end{tabular}




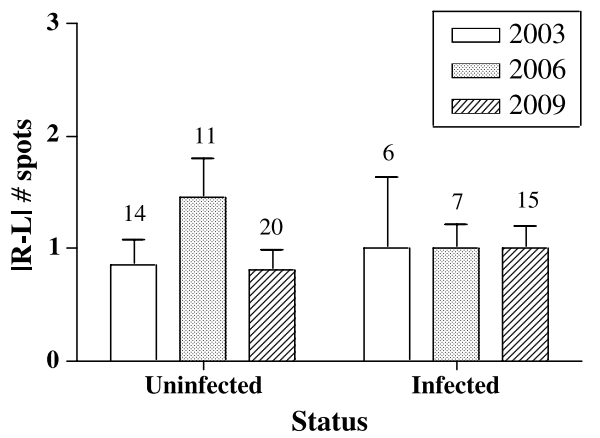

Figure 2. Mean absolute R-L spot number asymmetry ( $\pm 1 \mathrm{SE}$ ) of uninfected and infected newts of all three collection years. Results of ANOVA: year $p=0.47$; status $p=0.854$; year $\times$ status $p=0.47$.

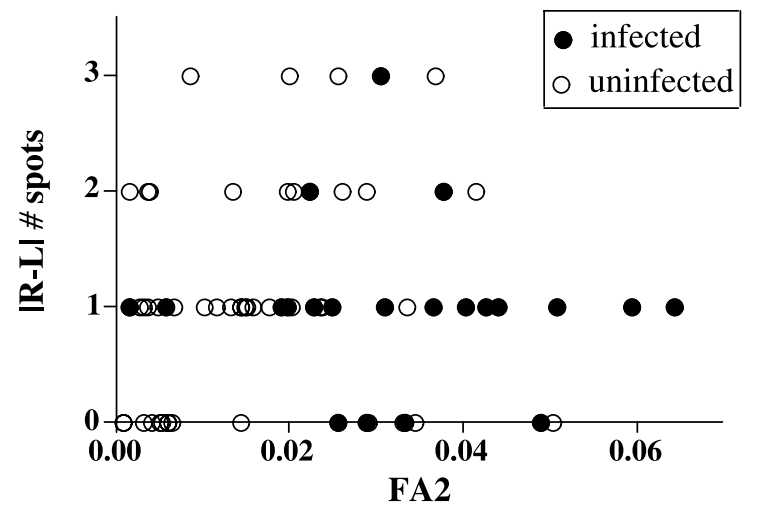

Figure 3. Absolute R-L spot number asymmetry as a function of hind leg FA2 in uninfected $(p=0.211)$ and infected $(p=0.763)$ newts.

In contrast to the results for hind limb FA2, infection status did not contribute significantly to variation in the absolute R-L difference in dorsal spot number (fig. 2). Neither was there any correlation between hind limb FA2 and the absolute $\mathrm{R}-\mathrm{L}$ difference in dorsal spot number in either infected $(p=0.763)$ or uninfected $(p=0.211)$ newts (fig. 3).

Finally, among infected individuals collected in 2006 and 2009, the extent of infection was not a predictor of FA2 ( $p=0.355$, fig. 4$)$.

\section{Discussion}

Prior research has established a link between susceptibility to pathogens and abnormal development. In our study, Ichthyophonus-sp. infected animals exhibited greater FA of the hind limbs than did uninfected animals (fig. 1). Our findings are consistent with two hypotheses that are not mutually exclusive. First, it is possible that newts with a lower capacity to buffer stresses occurring during development, as reflected in higher FA levels, might also be less able to resist Ichthyophonus-sp. 


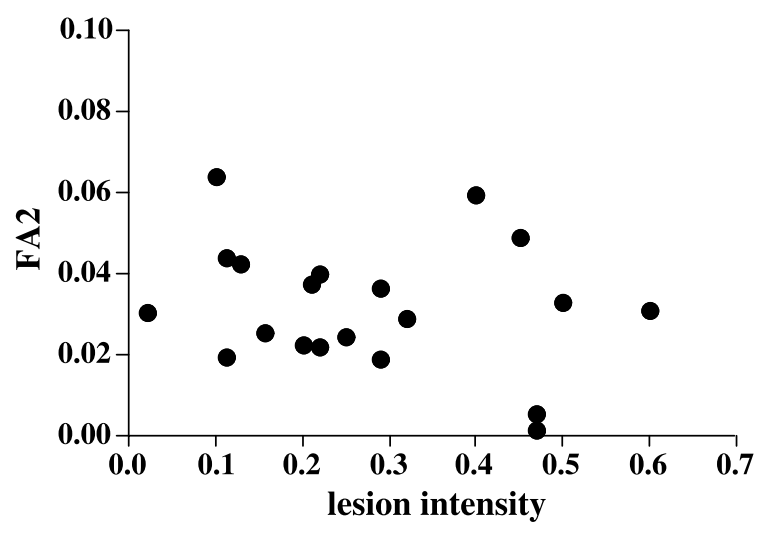

Figure 4. Hind leg FA2 as a function of the index of the extent of lesions $(p=0.355)$ for infected newts collected in 2006 and 2009.

infection. Second, it is also possible that infection may have fostered asymmetry. Parris and Cornelius (2004) demonstrated that frog and toad larvae reared in the presence of a fungus developed greater FA than control animals as a consequence. The course of Ichthyophonus infection in newts is unknown and deserves further investigation (Raffel et al., 2006). For example, we do not know when during ontogeny newts became infected. Nevertheless, if infection preceded the increase in FA, we might expect that newts with greater levels of infection should exhibit higher levels of FA but we found no such relationship (fig. 4). The absence of such a relationship may suggest that higher levels of FA indicate greater susceptibility to infection rather than having resulted from the effects of infection.

The pattern of greater hind limb FA in infected newts compared to uninfected individuals was more pronounced in the newts collected in 2006 and 2009 than in those from 2003 (fig. 1). The hind limb FA2 of infected animals was 18\% greater than that of uninfected animals in 2003, and roughly 130\% greater in 2006 and 2009. FA2 in uninfected newts did not differ significantly among the three study years (fig. 1). Thus, we have no evidence that all of the individuals in the newt population are more stressed as a whole. However, if the entire population is being exposed to conditions that are increasingly stressful and FA and vulnerability are both correlated with stress, with a threshold vulnerability for infection, we would expect to see the distributions of both uninfected and infected animals shifted towards higher values. We would expect higher FA levels on average in infected animals from a more stressed population, combined with higher prevalences. While there does not appear to be a dramatic change in the incidence of Ichthyophonus-sp. infection in our study (39\% of newts in 2003, $42 \%$ of newts in $2006,43 \%$ of newts in 2009) we will test this prediction as we continue to monitor this population. It is possible that some proportion of newts is exhibiting greater FA and these newts are similarly more prone to infection. Raffel et al. (2006) made a convincing argument that leeches transmit Ichthyophonus-sp. in newts. Our ongoing studies of this pop- 
ulation will include monitoring the prevalence of leeches and the incidence of the Ichthyophonus-sp. infection.

In contrast to the results for hind limb FA, spot number asymmetry was unrelated to infection status (fig. 2). Moreover, hind limb FA was not associated with spot number asymmetry (fig. 3). These latter results differ from those of Davis and Maerz (2007) who found that spot number asymmetry was correlated with hind limb asymmetry in spotted salamanders, Ambystoma maculatum. Unlike newts, however, whose spot pattern is set early in their ontogeny (Gill, 1978) it is not clear whether spot patterns remain fixed in Ambystoma throughout their lifetime. Nevertheless, given that mass was not a predictor of spot number asymmetry in Ambystoma, it is likely that the spot pattern is fixed and that spot number asymmetry is indeed a predictor of FA in other body regions in Ambystoma, reflecting the animal's susceptibility to stress (Davis and Maerz, 2007). The large variation in spot number asymmetry in newts and an absence of association with infection status (fig. 2) and hind limb FA (fig. 3) suggest that spot pattern of Notophthalmus may be less canalized than that of Ambystoma during development and perhaps, of less functional significance (Gonçalves et al., 2002). The cost of limb length asymmetry in newts may be greatest at later stages, such as when the limbs are needed to walk on land or clasp females. McCoy and Harris (2003) reported that conventional measures of fitness such as mass were not related to FA in spotted salamanders. These results are consistent with ours given that infected newts had greater hind limb FA (fig. 1) but the mass of infected and uninfected newts did not differ (table 1). Raffel et al. (2006) found that among infected newts, the intensity of the infection (comparable to our index of infection) was unrelated to mass. Similarly, in our study the extent of infection was not a predictor of hind limb FA (fig. 4).

Ongoing efforts to monitor the vitality of amphibian populations should include species, such as newts, that are not threatened or endangered at present (Beebee and Griffiths, 2005). Conservation efforts identifying populations that may become at risk could permit appropriate interventions (McCoy and Harris, 2003; Wright and Zamudio, 2002). Newts are important predators in freshwater ecosystems in eastern North America and, thus, their response to disease and other stressors can have a significant impact on the compositions of those ecosystems. The fact that infected newts had higher levels of hind limb FA than uninfected newts in our study suggests that hind limb FA may be a useful and non-invasive tool for identifying potentially vulnerable newt and other amphibian populations.

\section{Acknowledgements}

Ross Alford, Richard Wassersug and David Skelly made important suggestions on earlier drafts of this paper for which we are grateful. Two anonymous reviewers also made thoughtful comments on a recent draft that encouraged us to increase our sample size, which made our results more persuasive. Newts were collected under a permit from the Vermont Fish and Wildlife Department. The Bennington College Animal Care Committee oversaw the care of newts in the laboratory. This work was supported in part by funds from the American Wildlife Research Foundation and the National Science Foundation (OSR-9350540 to ES). 


\section{References}

Alford, R., Bradfield, K., Richards, S. (1999): Measuring and analyzing developmental instability as a tool for monitoring frog populations. In: Declines and Disappearances of Australian Frogs, p. 34-43. Campbell, A., Ed., Environment Australia, Canberra.

Alford, R.A., Bradfield, K.S., Richards, S.J. (2007): Ecology — global warming and amphibian losses. Nature 447: E3-E4.

Beebee, T.J.C., Griffiths, R.A. (2005): The amphibian decline crisis: a watershed for conservation biology? Biol. Conserv. 125: 271-285.

Blaustein, A.R., Wake, D.B. (1990): Declining amphibian populations: a global phenomenon. Trends Ecol. Evol. 5: 203-204.

Carey, C. (2000): Infectious disease and worldwide declines of amphibian populations, with comments on emerging diseases in coral reef organisms and in humans. Environ. Health Perspectives 108, Suppl. 1: 143-150.

Carey, C., Alexander, M.A. (2003): Climate change and amphibian declines: is there a link? Divers. Distrib. 9: 111-121.

Collins, J.P., Storfer, A. (2003): Global amphibian declines: sorting the hypotheses. Divers. Distrib. 9: 89-98.

Daszak, P., Berger, L., Cunningham, A.A., Hyatt, A.D., Green, D.E., Speare, R. (1999): Emerging infectious diseases and amphibian population declines. Emerg. Inf. Dis. 5: 735-748.

Daszak, P., Cunningham, A.A., Hyatt, A.D. (2003): Infectious disease and amphibian population declines. Divers. Distrib. 9: 141-150.

Davis, A.K., Maerz, J.C. (2007): Spot symmetry predicts body condition in spotted salamanders, Ambystoma maculatum. Appl. Herpetol. 4: 195-205.

Gill, D.E. (1978): The metapopulation ecology of the red-spotted newt, Notophthalmus viridescens (Rafinesque). Ecol. Monog. 48: 145-166.

Gonçalves, D.M., Simões, P.C., Chumbinho, A.C., Correia, M.J., Fagundes, T., Oliveira, R.F. (2002): Fluctuating asymmetries and reproductive success in the peacock blenny. J. Fish. Biol. 60: 810-820.

Green, D.E., Converse, K.A., Schrader, A.K. (2002): Epizootiology of sixty-four amphibian morbidity and mortality events in the USA, 1996-2001. Ann. N.Y. Acad. Sci. 969: 323-339.

Herman, R.L. (1984): Ichthyophonus-like infection in newts (Notophthalmus viridescens Rafinesque). J. Wild. Dis. 20: 55-56.

Kellner, J.R., Alford, R.A. (2003): The ontogeny of fluctuating asymmetry. Am. Nat. 161: 931-947.

McCoy, K.A., Harris, R.N. (2003): Integrating developmental stability analysis and current amphibian monitoring techniques: an experimental evaluation with the salamander Ambystoma maculatum. Herpetologica 59: 22-36.

Mikaelian, I., Ouellet, M., Pauli, B., Rodrigue, J., Harshbarger, J.C., Green, D.M. (2000): Ichthyophonus-like infection in wild amphibians from Quebec, Canada. Dis. Aq. Org. 40: 195201.

Møller, A.P. (2006): A review of developmental instability, parasitism and disease. Infect. Genet. Evol. 6: $133-140$.

Palmer, A.R. (1994): Fluctuating asymmetry analyses: a primer. In: Developmental Stability: Its Origins and Evolutionary Implications, p. 335-364. Markow, T.A., Ed., Dordrecht, Kluwer.

Parris, M.J., Cornelius, T.O. (2004): Fungal pathogen causes competitive and developmental stress in larval amphibian communities. Ecology 85: 3385-3395.

Pounds, J.A., Bustamante, M.R., Coloma, L.A., Consuegra, J.A., Fogden, M.P.L., Foster, P.N., La Marca, E., Masters, K.L., Merino-Viteri, A., Puschendorf, R., Ron, S.R., Sánchez-Azofeifa, 
G.A., Still, C.J., Young, B.E. (2006): Widespread amphibian extinctions from epidemic disease driven by global warming. Nature 439: 161-167.

Raffel, T.R., Dillard, J.R., Hudson, P.J. (2006): Field evidence for leech-borne transmission of amphibian Ichthyophonus sp. J. Parasitol. 92: 1256-1264.

Sherman, E. (2008): Thermal biology of newts (Notophthalmus viridescens) chronically infected with a naturally occurring pathogen. J. Therm. Biol. 33: 27-31.

Smith, K.G. (2006): Keystone predators (eastern newts, Notophthalmus viridescens) reduce impacts of an aquatic invasive species. Oecologia 148: 342-349.

Wright, A.N., Zamudio, K.R. (2002): Color pattern asymmetry as a correlate of habitat disturbance in spotted salamanders (Ambystoma maculatum). J. Herpetol. 36: 129-133.

Accepted: 15 August 2009. 